\title{
Superovulation Affects the Gene Expression Patterns of Mice Oocytes and Preimplantation Embryos Produced by Different Assisted Reproductive Technologies
}

\author{
Elhameh Jahanbakhsh-Asl $^{1^{\mathbb{D}}}$, Mohammad Salehi $^{2,3^{*}}{ }^{\mathbb{D}}$, Marefat Ghaffari-Novin $^{1}$, Yoko Kato ${ }^{4}$
}

\begin{abstract}
Objectives: In this experiment, possible effect of superovulation on important molecular profiles of oocytes and embryos were examined in mice regarding their development.

Materials and Methods: A total of 120 metaphase II oocytes were produced by super or spontaneous ovulation. Blastocyst-stage embryos were produced after in vitro fertilization (IVF) and in vivo fertilization. Blastocysts that have been obtained from naturally mated female without gonadotrophin treatment were also used as controls. Using real-time polymerase chain reaction (PCR), the mRNA expression patterns of Bone morphogenesis protein (Bmp 15), hepatoma-derived growth factor (Hdgf), DNA methyl transpherase-1 (Dnmt-1), developmental pluripotency associated 3 (Dppa3), and zinc finger protein 57 (Zfp57) genes were compared between superovulated and spontaneously ovulated oocytes; the expression patterns of $H 19$ and small nuclear ribonucleoprotein $\mathrm{N}($ Snrpn) imprinting genes between embryos produced from these oocytes were also compared.

Results: The results of the study showed that expression of five maternal effect genes (Bmp15, Hdgf, Dnmt-1, Dppa3, and Zfp57) in superovulated oocytes were significantly reduced $(P<0.05)$. However, the rates of cleavage to the blastocyst stages were not significantly different $(P<0.05)$ between superovulated and naturally ovulated oocytes in cultured embryos. Moreover, superovulation disturbed the expression patterns of imprinting genes (H19 and Snrpn) in single blastocysts obtained by different assisted reproductive techniques (ARTs).

Conclusions: The findings indicated that superovulation affected the molecular characteristics of ART conceived embryos.

Keywords: ART, Gonadotrophins, Superovulation, Epigenetics
\end{abstract}

\section{Introduction}

The assisted reproductive techniques (ARTs) are widely applied for fertility treatment and research purposes. Several innovations and improvements in various protocols of manipulation techniques and culture conditions have been introduced to increase the efficiency of these technologies. Oocyte collection methods using exogenous endocrine stimulation at the beginning of most ART protocols, however, have basically remained unchanged and raised one of the ongoing concerns of the safety of ART procedures (1).

Ovarian stimulation through the injection of gonadotrophins that is used to release greater number of oocytes than in spontaneous ovulation, exerts an extreme amount of pressure on ovarian follicles and oocytes in order to speed up growth and maturation, potentially influencing maternal reproductive system and development of the embryos derived from such oocytes. Indeed, numerous studies have repeatedly confirmed that superovulation leads to delayed embryo development, decreased implantation rate, and increased post- implantation loss (2-4).

Recent studies provide a growing body of evidence on significant association between ovarian stimulation and increased incidence of certain imprinting diseases including Beckwith-Wiedemann and Angelman syndromes in humans as well as imprinting defects in the mice $(5,6)$.

Methylation marks established on imprinted genes in the mouse are stably preserved during the second wave of genome-wide demethylation and remethylation occurs in the late blastocyst close to the time of implantation to maintain sex-specific monoallelic expression of gene imprints $(7,8)$. The establishment, maintenance, or acquisition of methylation marks during epigenetic reprogramming are thought to be vulnerable to some degree of error and may be disrupted due to various factors including exposure to certain environmental factors such as high doses of exogenous gonadotrophins $(4,6)$. The hypothesis of the epigenetic effects of superovulation are supported by several detailed reports showing aberrant DNA methylation of imprinted genes 
and increased incidence of epimutations in oocytes (9), embryos (10,11), and also fetuses and placentas (3) derived from superovulation. Moreover, observations of DNA methylation disruptions, in both maternally and paternally imprinted genes in mouse blastocysts derived from superovulated eggs (12) provide more insight into the reasons for methylation defects in blastocysts.

In fact, such disruptive effects of superovulation on the epigenetic reprogramming machinery may originate from the disorder of gene products stored in oocytes $(13,14)$. A large number of mRNAs and proteins named maternal effect genes aggregate during oocyte growth and cytoplasmic maturation. The processes of synthesis, storage, and function of these maternal transcripts strongly determine the quality and development potential of oocytes and embryos (15). Maternal effect genes that organize the transportation of methyl groups in the genome and chromatin modification of two pronuclei are essential for genome reprogramming processes after fertilization (16). Three maternal effect transcripts including DNA methyltransferase (Dnmt-1), developmental pluripotencyassociated (Dppa3) (also named Stella/PGC7), and Zinc finger protein $57(Z f p 57)$ have been identified to protect gene imprints from losing their established methylation marks during preimplantation development (13).

Enhancing the pace of nuclear maturation of oocytes in a large number of synchronized ovarian follicles by exogenous gonadotrophins results in accelerated follicle development and oocyte release before the completion of cytoplasmic maturation and adequate production of maternal-effect transcripts (6). It seems probable that the expression level of maternal effect genes required for imprint maintenance is altered by the influence of superovulation, which may in turn induce a range of imprinting errors during pre-implantation development (13). In the same way, various types of maternal effect genes critical for oocyte quality and proper embryo development may be deleteriously affected by superovulation. It was found that the viability and quality of superovulated oocytes in mice are not the same as those released from naturally ovulated animals (17).

Although there are some remarkable studies on the effects of gonadotrophins on epigenetic alterations focusing on methylation states of imprinting genes in mouse preimplantation embryos $(9-12,14)$, very little is known with ambiguities about the expression states of imprinting genes under the influence of hormonic treatment. Therefore, the expression states of genes controlling the epigenetic procedures and some crucial processes during oocyte maturation and embryo development under these conditions would be of interest. Based on the documented relationship between superovulation and the quality of oocyte and embryo, the objectives of this study were to further elucidate the mechanism (s) involved, including the effects of gonadotrophin treatment on gene expression levels of five maternal effect genes implicated in epigenetic reprogramming of imprints (Dnmt-1, Dppa3, and Zfp57) and oocyte quality (bone morphogenic factor 15 [Bmp15] and hepatoma-derived growth factor [Hdgf]) in oocytes and the type of gene expression aberrations of H19 (imprinted maternally expressed transcript [non-protein coding]) and small nuclear ribonucleoprotein $\mathrm{N}$ (Snrpn) imprinting genes potentially reflected in the conceived embryos. In addition, evaluation of the effect of ovarian stimulation on developmental progression of embryos was desired in parallel.

\section{Materials and Methods}

Different experimental groups of mice models were established to evaluate the effect of superovulation on the expression of selected imprint maintenance and maternal effect genes during the development of mouse oocytes to blastocyst stage (Figure 1).

\section{Reagents}

All the reagents were purchased from Sigma Aldrich (Germany) except for the pregnant mare serum gonadotrophin (Folligon, Intervent, Australia) and human chorionic gonadotrophin hormone (hCG, Sereno, Switzerland).

Animals

Adult male and female B6D2F1 (C57BL/63DBA/2) strain mice (6-8 weeks of age) and male mice (6-8 weeks of age) were used in this study. During the experiments, food and water were provided ad libitum; for the mice; the animals were maintained under a controlled temperature (23$25^{\circ} \mathrm{C}$ ) and 14 hours light (10 hours dark conditions).

Mature Oocyte Collection From Superovulated Ovaries MII oocytes are those that have extruded the first polar body. For ovarian stimulation, females were administered a single dose $(10 \mathrm{IU})$ of pregnant mare serum gonadotrophin followed by the same dosage of human chorionic gonadotropin (hCG) after 48 hours. Cumulusoocyte complexes were collected by tearing the oviducts

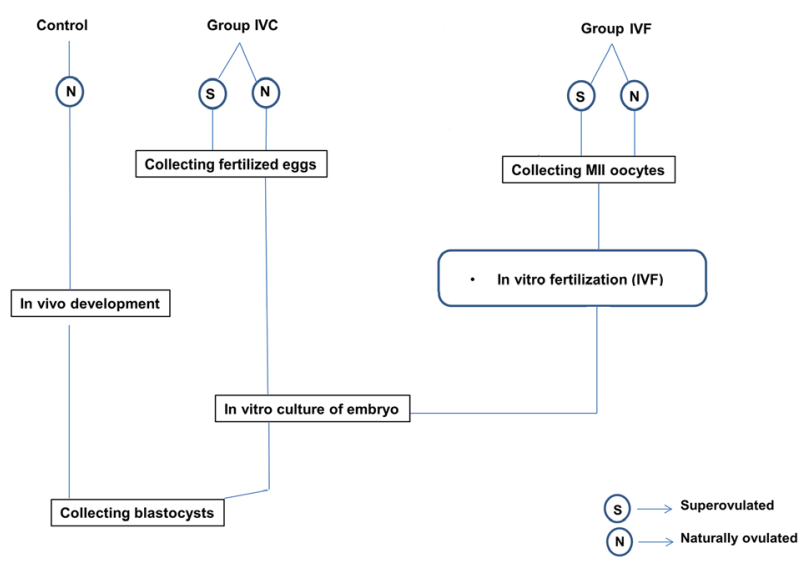

Figure 1. Experimental design for collecting different types of oocytes and embryos by different ARTs. 
13-14 hours after hCG injection and released into flushing holding medium (FHM). Cumulus cells were removed through pipetting in $0.03 \%(300 \mathrm{U} / \mathrm{mL})$ hyaluronidase in FHM medium for less than 3 minutes and denuded oocytes were extensively washed with FHM medium and prepared for the next step depending on the experiments. For oocyte studies, 10-15 morphologically normal oocytes were selected per mouse among 20-30 oocytes that each superovulated female produced an average.

Mature Oocyte Collection From Naturally Cycling Ovaries Naturally cycling female mice in the estrus were mated with vasectomized males maintained under the same conditions. Estrus in the females was identified by examining the color, moistness, and degree of swelling of the vagina. To set up mating, females were examined in the afternoon and those in estrus phase were placed in a cage with one stud vasectomized male in the evening before the day of oocyte collection. Following checking the vagina for a copulation plug (vaginal or mating plug), female mice were killed the next morning. The remaining process was the same as that for collecting the superovulated oocytes. Depending on the conditions, 5-8 naturally ovulated oocytes were obtained per female.

\section{In Vitro Fertilization}

The cumulus-oocyte complexes that were obtained from the oviducts, according to the same protocol described above for both types of oocytes, were kept in the incubator in $100 \mu \mathrm{L}$ fertilization drops of HTF medium supplemented with $4 \mathrm{mg} / \mathrm{mL}$ bovine serum albumin (BSA). Sperm obtained from the cauda epididymis of male mice were placed in $0.5 \mathrm{ml} \mathrm{HTF}$ medium and the sperm suspension was left at $37^{\circ} \mathrm{C}$ for 10 minutes and then centrifuged at $300 \mathrm{x}$ g for 3 minutes. Warm HTF medium $(0.5 \mathrm{~mL})$ was added to pellet after decanting the supernatant and maintained at $37^{\circ} \mathrm{C}$ and $5 \% \mathrm{CO} 2$ for 45 minutes. After the swim-up period, $100 \mu \mathrm{L}$ of sperm solution at a concentration of $5 \times 10^{6} \mathrm{sperm} / \mathrm{mL}$ was added to the fertilization drop containing the cumulus-oocyte complex and incubated for 6 hours. Successful fertilization of the eggs was determined based on the presence of two pronuclei and these eggs were transferred to $30 \mu \mathrm{L}$ drops of fresh $\mathrm{KSOM}^{\mathrm{AA}}$ culture medium supplemented with $4 \mathrm{mg} / \mathrm{mL}$ BSA and containing natural amino acids (Eagle's essential and non-essential amino acids, AA). The concentrations of AAs added to KSOM were according to a protocol described by Eagle (18). The KSOM ${ }^{\mathrm{AA}}$ medium droplets were covered with mineral oil, and then placed at $37^{\circ} \mathrm{C}, 5.5 \% \mathrm{CO} 2$ in humidified air. Culture of the fertilized oocytes was continued until they reached the blastocyst stage.

\section{Collection of Fertilized Eggs}

In vivo embryos at the one cell stage (fertilized eggs at the zygote stage) were obtained from females mated individually with males just after either second round of hCG or no gonadotrophin treatment. Twenty-one hours after the caging, fertilized eggs were separately collected from superovulated and spontaneously ovulated females with a vaginal plug. After denudation and washes, both types of fertilized oocytes containing 2 pronuclei in each, were separately cultured in $\mathrm{KSOM}^{\mathrm{AA}}$ media supplemented with $4 \mathrm{mg} / \mathrm{mL}$ bovine serum albumin under similar conditions as described for in vitro fertilization (IVF). Embryos obtained from this in vivo fertilization method and in vitro culture were defined as IVC group.

\section{Collection of Blastocysts}

Naturally cycling females without gonadotrophin stimulation were caged with BDF1 males and pregnancy was determined by the presence of a vaginal plug the following morning (day 0.5). The genital tracts of females at day 3.5 postcoitum were flushed using FHM medium to recover blastocyst-stage embryos. Embryos obtained were used as the control group.

\section{Embryo Cleavage Assessment}

The kinetics of in vitro cultured embryo cleavages were determined by daily observations (from days 1 to 4 ) under an inverted microscope with Hoffman Modulation Contrast optics (TE2000-S - Nikon) at 200× magnification.

\section{Simultaneous RNA Isolation and cDNA Synthesis}

Every 10 morphologically normal fresh oocytes from spontaneously and superovulated females were pooled as a sample group for cDNA synthesis. The cDNA synthesis was then performed on individual blastocysts. Extraction of the total RNA from oocytes and embryos, complementary DNA (cDNA) synthesis, and quantitative reverse transcription (RT) polymerase chain reaction (PCR) analysis were carried out as previously described $(19,20)$. Briefly, denuded MII oocytes and expanded blastocysts were washed in phosphate buffered saline/ polyvinyl alcohol buffer before pipetting into Eppendorf tubes containing lysis buffer. The cDNA was synthesized by addition of $100 \mathrm{pM}$ concentration of random hexamer and nuclease free water to each sample. The samples were placed in a Bio-Rad thermocycler for 5 minutes at $75^{\circ} \mathrm{C}$ for the reaction to take place. Then, for RT, the tubes were placed on ice; next, 5x RT buffer, 200 U RT enzyme, 10 $\mathrm{mM}$ dNTP, and $10 \mathrm{U}$ RNase inhibitor were added to the reaction as well. The $\mathrm{RT}$ reaction was carried out at $25^{\circ} \mathrm{C}$ (10 minutes), $37^{\circ} \mathrm{C}$ ( 15 minutes), $42^{\circ} \mathrm{C}$ ( 45 minutes), and $75^{\circ} \mathrm{C}$ (10 minutes). The samples were maintained at $4^{\circ} \mathrm{C}$ overnight and stored at $-20^{\circ} \mathrm{C}$.

\section{Quantitative Real-Time PCR Assays}

The primers used for quantitative PCR, products sizes, and Gen-Bank accession numbers are shown in Table 1. The mRNA expression of each primer in the oocytes and blastocysts was quantified using Rotor-Gene Q 
Table 1. Details of Primers Used for the Real-Time PCR Analysis

\begin{tabular}{|c|c|c|c|}
\hline Gene & Primer Sequence & Product Size (bp) & Gene Bank Accession No. \\
\hline \multirow{2}{*}{ Hprt1 } & F:T CCCAGCGTCGTGATTAG & \multirow{2}{*}{137} & \multirow{2}{*}{ NM_013556.2 } \\
\hline & R:CGAGCAAGTCTTTCAGTCC & & \\
\hline \multirow{2}{*}{ Dnmt1 } & F:A CACCGTTCCCGTTCAG & \multirow{2}{*}{154} & \multirow{2}{*}{ NM_001199431.1 } \\
\hline & R:TCATCCACAGCATCCTCAG & & \\
\hline \multirow{2}{*}{ Bmp15 } & F:G CTCAAGTTATACCATCGTTCG & \multirow{2}{*}{192} & \multirow{2}{*}{ NM_009757.4 } \\
\hline & R: TGGCTCTGATTAGTTCGTATGC & & \\
\hline \multirow{2}{*}{$H d g f$} & F:T GAGGAGGAGGACAAGGAG & \multirow{2}{*}{196} & \multirow{2}{*}{ NM_008231.4 } \\
\hline & R:TGGTGGCTACAGGCTCTC & & \\
\hline \multirow{2}{*}{ Zfp57 } & F:A ACAGTCTTCCCAGCCATCC & \multirow{2}{*}{167} & \multirow{2}{*}{ NM_001013745.2 } \\
\hline & R:AGGTTTCTTCTTGCTTCCGAC & & \\
\hline \multirow{2}{*}{ Dppa3 (Stella/Pgc7) } & F: G GGTCCGCACTTTGTTG & \multirow{2}{*}{110} & \multirow{2}{*}{ NM_139218.1 } \\
\hline & R:GTCCCGTTCAAACTCATTTC & & \\
\hline \multirow{2}{*}{ H19 } & F: AGAACCACTACACTACCTGC & \multirow{2}{*}{97} & \multirow{2}{*}{ NR_130974.1 } \\
\hline & R:TGGGTGCTATGAGTCTGC & & \\
\hline \multirow{2}{*}{ Snrpn } & F:A GGAAGATCAAGCCAAAGAATGC & \multirow{2}{*}{148} & \multirow{2}{*}{ NM_001082961.1 } \\
\hline & R:CAAGAGGCACACGAGCAATG & & \\
\hline
\end{tabular}

instrument (QIAGEN). Based on the manufacturer's instructions for DNA Master SYBR Green I mix (Roche Applied Sciences), the real-time PCR was performed manually in duplicates for each sample, in a final volume of $13 \mu \mathrm{L}$. The concentration of each primer was adjusted to $1 \mu \mathrm{M}$ for each of the genes and $1 \mu \mathrm{M}$ for synthesized cDNA. The mRNA level of the Hprt1 housekeeping gene was used for normalization of mRNA level of each sample amplified with real-time PCR as the endogenous internal reference gene. Hprt1 expression in oocytes and blastocysts was found to be stable using PCR under the present experimental conditions before applying it as a positive control for normalization. Non-template controls were processed by including target genes with no-template in each run.

\section{Statistical Analysis}

Relative gene expression levels of the studied genes among oocytes and embryos of all the groups were analyzed using REST (relative expression software tool) 2009 software (QIAGEN). All statistical analyses of the values related to gene expression levels of each comparative sample obtained from REST software were performed using SPSS software version 16 . Independent samples $t$ test was used to evaluate the statistical significance of the differences of values between each comparative group. The results of in vitro development of embryos to the blastocyst stage were compared using non-parametric Mann-Whitney rank test for normalization of the data containing nonnormal distribution of values. All the data were expressed as means \pm standard deviation (SD). The significance threshold was set at $5 \%(P<0.05)$.

\section{Results}

Effect of Superovulation on mRNA Expression Patterns of Candidate Maternal Effect Genes in Oocytes

As previously mentioned, a total of $60 \mathrm{MII}$ oocytes were collected from 5 superovulated females and 10 naturally ovulated ones. Based on relative quantification of mRNA, significantly lower expression of all the 5 maternal effect genes (Bmp15, Hdgf, Dnmt-1, Dppa3, and Zfp57) was found in superovulated MII oocytes when compared with naturally ovulated oocytes $(P<0.05$, Figure 2$)$. The expression of three methylation regulating genes, that is, Dnmt1, Dppa3, and Zfp57 in the superovulated group was reduced by $30 \%-50 \%$ when compared with the natural oocytes. Similarly, the expression of Hdgf and Bmp15 was reduced to less than $50 \%$ and $20 \%$, respectively compared with the natural oocytes.

Effect of Superovulation on Development of Embryos Obtained by Different Fertilization Methods

As shown in Table 2, the proportions of cleaving embryos and blastocyst formation did not differ significantly between the embryos from superovulated and naturally ovulated oocytes in the IVC and IVF groups.

Effect of Superovulation on mRNA Expression Patterns of Candidate Genes in Blastocysts Obtained by Different Methods of Fertilization

For H19 and Snrpn genes, quantitative real-time PCR was replicated in 15 to 25 blastocysts obtained from both natural and superovulated oocytes separately in each experimental group and 10 blastocysts developed and obtained in vivo as control group. According to relative 


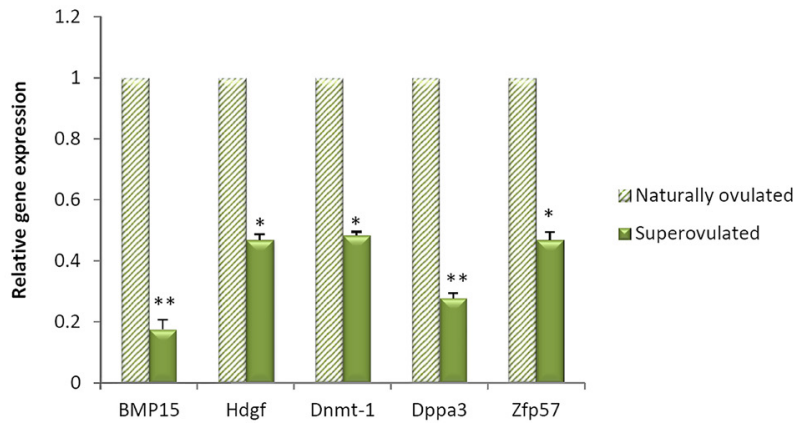

Figure 2. Expression of maternal effect genes in spontaneously and superovulated oocytes in the gene expression states of Bmp15, Hdgf, Dnmt1, and Zfp57 in oocytes collected from gonadotrophintreated females $(n=60)$ are lower than those expressed in oocytes collected from naturally ovulated females $(n=60)$. Error lines within bars indicate SD. * Statistically significant different at $P<0.05$; ** Statistically significant different at $P<0.01$

quantification of mRNA, significantly lower expression of the H19 and Snrpn genes was found in single blastocyststage embryos from naturally ovulated oocytes in the IVC and IVF experimental groups when compared with the control blastocysts $(P<0.05)$. However, the mean relative $H 19$ and Snrpn mRNA expression levels were not significantly reduced among IVC-and IVF-derived blastocysts from superovulated oocytes compared with both naturally ovulated oocytes and control groups (Figure 3). The H19 and Snrpn gene expression patterns in the blastocysts from superovulated oocytes exhibited both increasing and decreasing amounts of relative mRNAs with almost equal distributions compared with blastocysts from naturally ovulated oocytes and control blastocysts in all the experimental groups (Figures 4 and 5).

\section{Discussion}

An overall significant down-regulation of examined maternal effect genes was found in superovulated oocytes compared with naturally ovulated oocytes. The products of Bmp15 and Hdgf maternal effect genes were growth factors synthesized by maturing oocytes, secreted in the follicular fluid (FF), and implicated in oocyte maturation and fertilization by their autocrine effects on oocytes and paracrine effects on granulosa cells $(15,21)$. In particular, it is stated that the amount of Bmp15 in FF is an important molecular marker that determines oocyte quality and

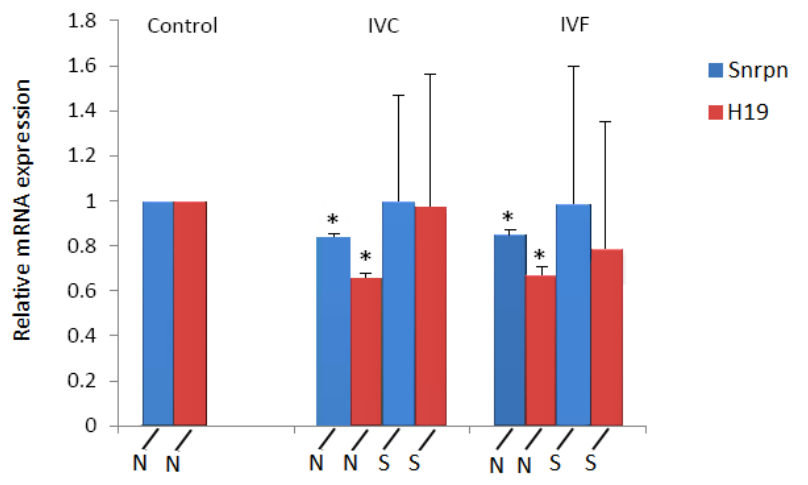

Figure 3. Relative mRNA quantities (means \pm SD) of Snrpn and H19 genes in embryos obtained from differently treated mouse.

Note. N: blastocysts obtained from naturally ovulated oocytes; s: blastocysts obtained from superovulated oocytes; "Significant downregulation as compared to the control at $P<0.05$.

proper embryo development due to its crucial role in prompting mitosis and proliferation of granulosa cells required for cumulus cell expansion (22). Reduced gene expressions observed in Bmp15 and Hdgf growth factors in superovulated oocytes could have adverse effects on quality and maturation procedures of oocytes, potentially giving a rise to reduced development potential.

According to the findings of the experiments conducted in this study, ovarian stimulation also affected the expression levels of three other maternal effect genes (Dnmt-1, Dppa3, and Zfp57) implicated in epigenetic reprogramming in oocytes. As has been pointed out, Dnmt1 is the primary maintenance methyltransferase responsible for restoration of methylation pattern after DNA replication (6). Besides, Zfp57 maintains both maternal and paternal imprints (23), and Dppa3 protects imprints from DNA methylation in early embryogenesis (24). Based on the crucial roles of these maternal effect genes, the expression state of these genes encoding accessory proteins was involved in the establishment and protection of appropriate methylation profiles in imprints is regulated carefully during pre-implantation development. For Dnmt1, the current result conflicts with an earlier study on ICR mice in which the expression state of Dnmt1 did not differ between superovulated and naturally ovulated oocytes (14). This discrepancy may be explained by the differences in experimental conditions

Table 2. Developmental Outcome of Differently Fertilized Embryos From Superovulated and Naturally Ovulated Oocytes

\begin{tabular}{|c|c|c|c|c|c|c|}
\hline \multirow{2}{*}{$\begin{array}{l}\text { Collection } \\
\text { Method of Oocytes }\end{array}$} & \multirow{2}{*}{$\begin{array}{l}\text { No. of Used } \\
\text { Animals }\end{array}$} & \multicolumn{2}{|l|}{ Day 0} & \multirow{2}{*}{$\begin{array}{l}\text { Day } 1 \\
\text { Cleaved/Fertilized } \\
(\% \text { mean } \pm \text { SD) }\end{array}$} & \multirow{2}{*}{$\begin{array}{l}\text { Day 2-3 } \\
4-16 \text { Cell } \\
(\% \text { mean } \pm \text { SD) }\end{array}$} & \multirow{2}{*}{$\begin{array}{l}\text { Day } 4 \\
\text { Blastocyst } \\
\text { (\% mean } \pm \text { SD) }\end{array}$} \\
\hline & & $\begin{array}{l}\text { No. of Collected } \\
\text { Oocytes }\end{array}$ & $\begin{array}{l}\text { Fertilization } \\
\text { Method }\end{array}$ & & & \\
\hline Superovulation & 3 & 67 & IVC & $64.67(95.5 \pm 4.3)$ & $62(92 \pm 6.5)$ & $58(86 \pm 3.6)$ \\
\hline Natural ovulation & 7 & 48 & IVC & $47.48(98 \pm 2.7)$ & $45(93.7 \pm 4.7)$ & $42(87.5 \pm 9.0)$ \\
\hline Superovulation & 3 & 62 & IVF & $52.60(85.6 \pm 6.0)$ & $52(85.6 \pm 6.0)$ & $49(80.3 \pm 7.5)$ \\
\hline Natural ovulation & 5 & 36 & IVF & $33.36(91.5 \pm 1.1)$ & $32(88.5 \pm 6.0)$ & $30(83.1 \pm 9.3)$ \\
\hline
\end{tabular}




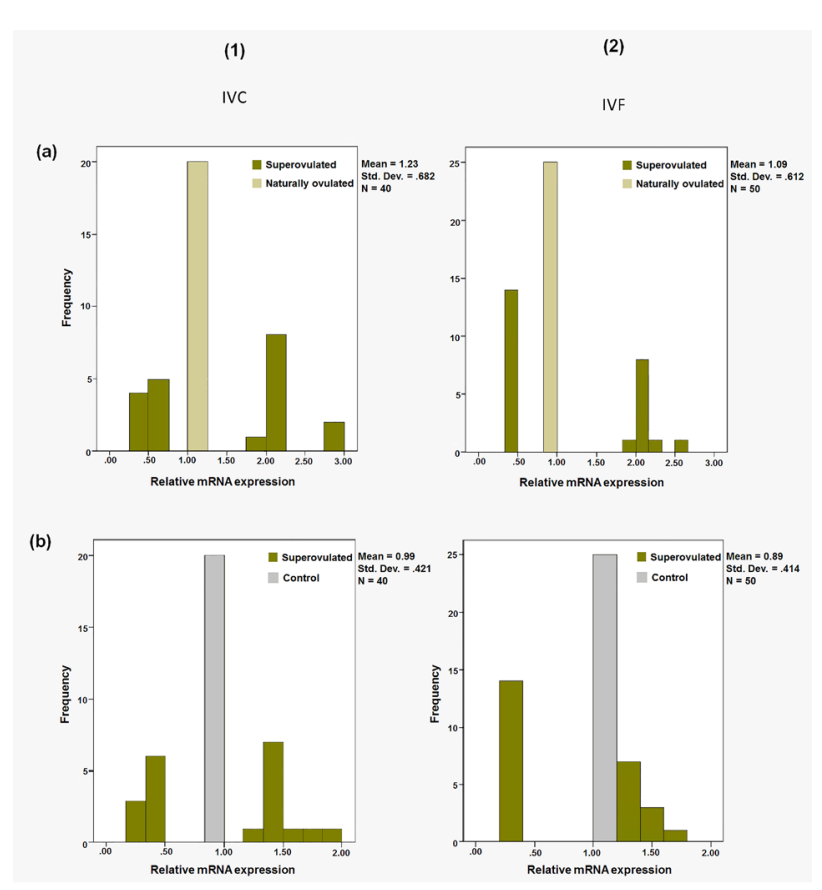

Figure 4. Distribution of relative mRNA quantities (means $\pm S D$ ) of $\mathrm{H} 19$ in blastocysts obtained from superovulated oocytes in IVC (a1, b1) and IVF (a2, b2) groups when compared with the corresponding ones obtained from naturally ovulated oocytes (a1, a2) and control blastocysts (b1, b2). $\mathrm{N}=$ total number of analyzed embryos in comparative groups.

such as the difference between BDF1 (outbred) and ICR (hybrid) mouse strains, different culture conditions, different gene expression analysis techniques, or other unknown causes which could produce different results in these types of experiments. Therefore, further studies considering different species and using larger data are needed in order to obtain more precise results in this regard. Nevertheless, the findings of the present study support the hypothesis that the evident epigenetic side effects of superovulation can be due in part to the clear disruptive effects of superovulation on gene expression states of maternal effect genes required for imprint maintenance during oogenesis and early embryogenesis.

Two imprinted genes expressed at high levels in blastocysts were H19 and Snrpn (small nuclear ribonucleoprotein $\mathrm{N}$ ). As has been suggested, maternal H19 gene expression begins at the blastocyst stage whereas paternal transcription of the Snrpn gene begins at the 4-cell stage (25). Lower expression levels of H19 and Snrpn imprinting genes in IVC-and-IVF-derived blastocysts from naturally ovulated oocytes could be due to factors other than superovulation including environmental manipulation.

The H19 and Snrpn expression levels in IVC-and IVFderived blastocysts were not significantly different from those in superovulated oocytes when compared with both naturally ovulated and control groups, likely due to high variability of H19 and Snrpn expressions in each

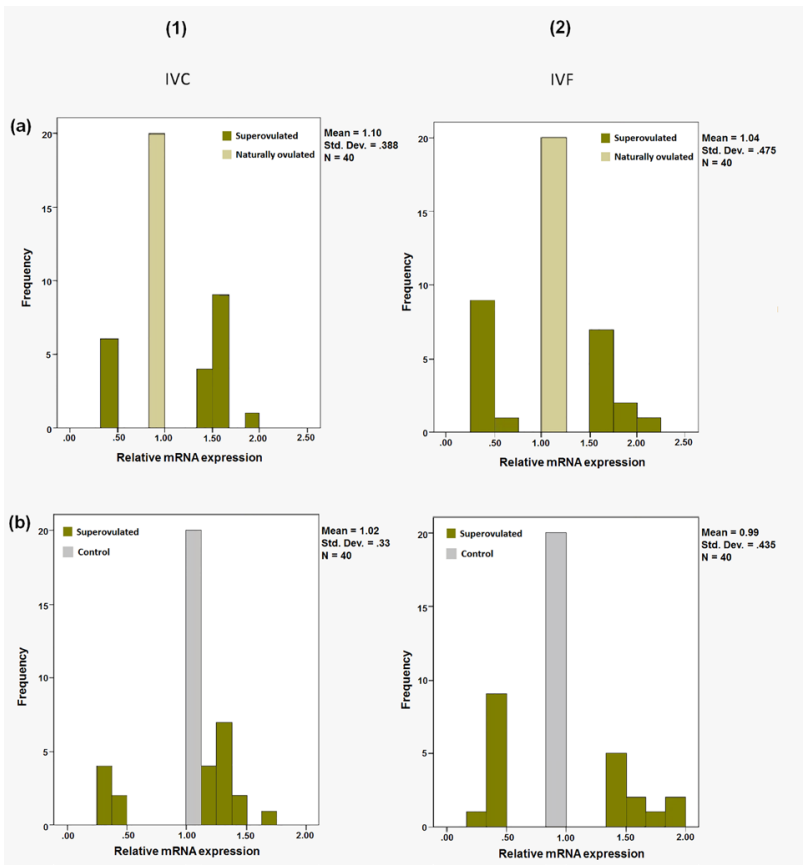

Figure 5. Distribution of relative mRNA quantities (means $\pm S D$ ) of Snrpn in blastocysts obtained from superovulated oocytes in IVC (a1, b1) and IVF (a2, b2) groups when compared with corresponding ones obtained from naturally ovulated oocytes (a1, a2) and control blastocysts (b1, b2). $\mathrm{N}=$ total number of analyzed embryos in comparative groups.

group. Interestingly, disrupted expression patterns of both H19 and Snrpn were observed in blastocysts from superovulated oocytes in all the experimental groups. It is probable that such disrupted expression patterns mainly originated from the aberrant patterns of methylation previously reported in blastocysts from superovulated oocytes as compared with naturally ovulated oocytes.

Methylation alterations due to the influence of gonadotrophins were well explained in the study by Market-Velker et al who compared the methylation states of H19 and Snrpn imprinting genes between embryos conceived from superovulated and naturally ovulated females. They found different degrees of loss and gain of methylation in both maternal and paternal alleles of H19 and Snrpn genes in blastocysts obtained from superovulated mice with a high hormone dosage (10 IU) as compared with their control group (12). These alterations in the methylation level of imprinting genes could explain disrupted expression patterns of H19 and Snrpn genes observed in the superovulated groups, if methylation defects were the primary cause of abnormalities in the gene expression level. These types of disturbances in imprinted gene expression were also reported by Fauque et al (11). Comparing H19 gene expression between different types of embryos conceived from superovulated oocytes and embryos conceived from naturally ovulated mice, they found that $H 19$ expression was highly variable in each group (11). 
Moreover, the tendency of gene expression values towards certain ratios in naturally ovulated and control groups, both decreases and increases, was probably the final result of the interactions between several effects including different degrees of methylation alterations and environmental manipulation. It is probable that other factors implicated in epigenetics such as acetylation states, in imprints were also influenced by superovulation and would have an interference effect on this complicated process; their possible effects on these factors need to be investigated in future studies. However, the present investigation obviously showed that general vulnerability of epigenetics to the environmental stressors that have been suggested several times in earlier reports $(26,27)$, clearly reflected the disrupted patterns of the gene expression levels of the studied imprints in the pre-implantation embryos under the influence of gonadotrophin treatment.

\section{Conclusions}

Taken together, the results of this study suggested that gonadotrophin treatment affected molecular profile of both oocytes and preimplantation embryos implicated in oocyte quality and embryo development in many different ways, respectively. If the variations in the gene expression patterns exceeded a specific level with/without a combination of genes, developmental ability could be affected or long time effects might manifest during the lifetime of the offspring.

\section{Conflict of Interests}

Authors declare that they have no conflict of interests.

\section{Ethical Issues}

All the experiments and protocols were performed in strict accordance with the Guiding Principles for the Care and Use of Research Animals adopted by Shahid Beheshti University of Medical Sciences Committee on Animal Research and Bioethics (ethical No. 66000625).

\section{Financial Support}

This research project was financially supported by Urogenital Stem Cell Research Center, Shahid Beheshti University of Medical Sciences, Tehran, Iran.

\section{Acknowledgements}

This work was performed under auspices of the Department of Transgenic Animal Science, Stem Cell Technology Research Center, Tehran, Iran. Micromanipulation training was conducted in Laboratory of Animal Reproductive, College of Agriculture, Kinki University, Nara, Japan under the allowance and managing of professor Y. Kato.

\section{References}

1. Halliday J, Wilson C, Hammarberg K, et al. Comparing indicators of health and development of singleton young adults conceived with and without assisted reproductive technology. Fertil Steril. 2014;101(4):1055-1063. doi:10.1016/j.fertnstert.2014.01.006

2. Ertzeid G, Storeng R. Adverse effects of gonadotrophin treatment on pre- and postimplantation development in mice. J Reprod Fertil. 1992;96(2):649-655.

3. Fortier AL, Lopes FL, Darricarrere N, Martel J, Trasler JM. Superovulation alters the expression of imprinted genes in the midgestation mouse placenta. Hum Mol Genet. 2008;17(11):1653-1665. doi:10.1093/hmg/ddn055

4. Van der Auwera I, D'Hooghe T. Superovulation of female mice delays embryonic and fetal development. Hum Reprod. 2001;16(6):1237-1243.

5. Iliadou AN, Janson PC, Cnattingius S. Epigenetics and assisted reproductive technology. J Intern Med. 2011;270(5):414-420. doi:10.1111/j.13652796.2011.02445.x

6. de Waal E, McCarrey JR. Effects of exogenous endocrine stimulation on epigenetic programming of the female germline genome. Anim Reprod. 2010;7(3):154-164.

7. Hajkova P. Epigenetic reprogramming--taking a lesson from the embryo. Curr Opin Cell Biol. 2010;22(3):342-350. doi:10.1016/j.ceb.2010.04.011

8. Morgan HD, Santos F, Green K, Dean W, Reik W. Epigenetic reprogramming in mammals. Hum Mol Genet. 2005;14 Spec No 1:R47-58. doi:10.1093/hmg/ddi114

9. Sato A, Otsu E, Negishi H, Utsunomiya T, Arima T. Aberrant DNA methylation of imprinted loci in superovulated oocytes. Hum Reprod. 2007;22(1):26-35. doi:10.1093/ humrep/del316

10. de Waal E, Yamazaki Y, Ingale P, Bartolomei MS, Yanagimachi R, McCarrey JR. Gonadotropin stimulation contributes to an increased incidence of epimutations in ICSI-derived mice. Hum Mol Genet. 2012;21(20):44604472. doi: $10.1093 / \mathrm{hmg} / \mathrm{dds} 287$

11. Fauque P, Jouannet P, Lesaffre C, et al. Assisted Reproductive Technology affects developmental kinetics, H19 Imprinting Control Region methylation and $\mathrm{H} 19$ gene expression in individual mouse embryos. BMC Dev Biol. 2007;7:116. doi:10.1186/1471-213x-7-116

12. Market-Velker BA, Zhang L, Magri LS, Bonvissuto AC, Mann MR. Dual effects of superovulation: loss of maternal and paternal imprinted methylation in a dose-dependent manner. Hum Mol Genet. 2010;19(1):36-51. doi:10.1093/ hmg/ddp465

13. Denomme MM, Mann MR. Genomic imprints as a model for the analysis of epigenetic stability during assisted reproductive technologies. Reproduction. 2012;144(4):393409. doi:10.1530/rep-12-0237

14. Liang XW, Cui XS, Sun SC, et al. Superovulation induces defective methylation in line-1 retrotransposon elements in blastocyst. Reprod Biol Endocrinol. 2013;11:69. doi:10.1186/1477-7827-11-69

15. Bogacki M, Wasielak M, Kitewska A, Bogacka I, Jalali BM. The effect of hormonal estrus induction on maternal effect and apoptosis-related genes expression in porcine cumulusoocyte complexes. Reprod Biol Endocrinol. 2014;12:32. doi:10.1186/1477-7827-12-32

16. Linke M, May A, Reifenberg $K$, Haaf $T$, Zechner U. The impact of ovarian stimulation on the expression of 
candidate reprogramming genes in mouse preimplantation embryos. Cytogenet Genome Res. 2013;139(2):71-79. doi: $10.1159 / 000343755$

17. Fulka J Jr, Fulka H. Somatic Cell Nuclear Transfer (SCNT) in Mammals. In: Sutovsky P, ed. Somatic Cell Nuclear Transfer. New York, NY: Springer; 2007:93-102.

18. Eagle H. Amino acid metabolism in mammalian cell cultures. Science. 1959;130(3373):432-437.

19. Dehghani-Mohammadabadi M, Salehi M, Farifteh F, et al. Melatonin modulates the expression of BCL-xl and improve the development of vitrified embryos obtained by IVF in mice. J Assist Reprod Genet. 2014;31(4):453-461. doi:10.1007/s10815-014-0172-9

20. Zuccotti M, Boiani M, Ponce R, et al. Mouse Xist expression begins at zygotic genome activation and is timed by a zygotic clock. Mol Reprod Dev. 2002;61(1):14-20. doi:10.1002/ mrd.1126

21. Cui XS, Li XY, Yin XJ, Kong IK, Kang JJ, Kim NH. Maternal gene transcription in mouse oocytes: genes implicated in oocyte maturation and fertilization. J Reprod Dev. 2007;53(2):405-418.

22. Wu YT, Tang L, Cai J, et al. High bone morphogenetic protein-15 level in follicular fluid is associated with high quality oocyte and subsequent embryonic development. Hum Reprod. 2007;22(6):1526-1531. doi:10.1093/humrep/ dem029

23. Li X, Ito M, Zhou F, et al. A maternal-zygotic effect gene, Zfp57, maintains both maternal and paternal imprints. Dev Cell. 2008;15(4):547-557. doi:10.1016/j.devcel.2008.08.014

24. Nakamura T, Arai Y, Umehara H, et al. PGC7/Stella protects against DNA demethylation in early embryogenesis. Nat Cell Biol. 2007;9(1):64-71. doi:10.1038/ncb1519

25. Mann MR, Chung YG, Nolen LD, Verona RI, Latham KE, Bartolomei MS. Disruption of imprinted gene methylation and expression in cloned preimplantation stage mouse embryos. Biol Reprod. 2003;69(3):902-914. doi:10.1095/ biolreprod.103.017293

26. Furrow RE, Christiansen FB, Feldman MW. Environmentsensitive epigenetics and the heritability of complex diseases. Genetics. 2011;189(4):1377-1387. doi:10.1534/ genetics.111.131912

27. Nagy C, Turecki G. Sensitive periods in epigenetics: bringing us closer to complex behavioral phenotypes. Epigenomics. 2012;4(4):445-457. doi:10.2217/epi.12.37

C 2018 The Author (s); This is an open-access article distributed under the terms of the Creative Commons Attribution License (http://creativecommons.org/licenses/by/4.0), which permits unrestricted use, distribution, and reproduction in any medium, provided the original work is properly cited. 